\title{
A cultura da corpolatria na pós modernidade e 0 deficiente físico: uma reflexão acerca dessa lógica binária
}

The culture of corpolatry in post modernity and the physical handicap: a reflection on this binary logic

\section{La cultura de la corolatría en la posmodernidad y el deficiente físico: una reflexión acerca de esa lógica binaria}

\author{
* Fabricio de Paula Santos \\ Mestre pela Universidade (FUMEC), Belo Horizonte, Minas Gerais, Brasil. \\ fabricio_fps@yahoo.com.br \\ ** Juliana Pontes Ribeiro \\ Doutora pela Universidade federal de Minas Gerais (UFMG), Belo Horizonte, Minas Gerais, Brasil. \\ fabricio_fps@yahoo.com.br
}

Recebido em 17 de junho de 2018

Aprovado em 16 de outubro de 2018

Publicado em 06 de maio de 2019

\section{RESUMO}

O presente ensaio tem como foco temático analisar como o corpo é realçado na pós modernidade, através da corpolatria, e como o corpo do deficiente físico é desvalorizado ou não evidenciado neste contexto. Tem como objetivo discutir como a corpolatria é fortemente influenciada e ditada pela mídia, exacerbando o narcisismo e colocando a forma física bela e referencial em evidência. Reflete acerca da lógica binária entre o culto ao corpo e as pessoas com deficiência física que se encontram fora dos padrões do corpo perfeito ou referencial, preestabelecido pela sociedade. Discute como os estereótipos são criados culturalmente e como eles influenciam de forma negativa ou pejorativa nas minorias sociais. Faremos a teorização dos problemas enfrentados por esta minoria social, tendo como base os teóricos dos estudos culturais. Por fim, evidencia como o corpo se torna um importante objeto que apresenta ou representa os indivíduos nas relações sociais a partir do outro.

Palavras-chave: Corpolatria; Corpo; Deficiência.

\begin{abstract}
The present essay focuses on how the body is emphasized in postmodernity through colorpolatry, and how the body of the physically handicapped is devalued or not evidenced in this context. Its purpose is to discuss how colorpollation is strongly influenced and dictated by the media, exacerbating narcissism and placing the beautiful and referential physical form in evidence. It reflects on the binary logic between body worship and people with physical
\end{abstract}


http://dx.doi.org/10.5902/1984686X33142

disabilities that are outside the standards of the perfect or referential body, pre-established by society. It discusses how stereotypes are culturally created and how they influence negatively or pejoratively in social minorities. We will theorize the problems faced by this social minority, based on cultural studies theorists. Finally, it shows how the body becomes an important object that presents or represents individuals in social relations from the other.

Keywords: Corpolatria; Body; Disability.

\section{RESUMEN}

El presente ensayo tiene como foco temático analizar cómo el cuerpo es realzado en la posmodernidad, a través de la corolatría, y cómo el cuerpo del deficiente físico es desvalorizado o no evidenciado en este contexto. Tiene como objetivo discutir cómo la corolatría es fuertemente influenciada y dictada por los medios, exacerbando el narcisismo y colocando la forma física bella y referencial en evidencia. Refleja sobre la lógica binaria entre el culto al cuerpo y las personas con discapacidad física que se encuentran fuera de los patrones del cuerpo perfecto o referencial, preestablecido por la sociedad. Discuta cómo los estereotipos se crean culturalmente y cómo influyen de forma negativa o peyorativa en las minorías sociales. Haremos la teorización de los problemas enfrentados por esta minoría social, teniendo como base los teóricos de los estudios culturales. Por último, evidencia cómo el cuerpo se convierte en un importante objeto que presenta o representa a los individuos en las relaciones sociales a partir del otro.

Palabras clave: Altas habilidades / superdotación; Piaget; Noción de justicia; Educación.

\section{Introdução}

É muito comum vermos nas redes sociais pessoas exibindo corpos cada vez mais magros, definidos e malhados através de fotos e vídeos em academias de ginástica ou praticando alguma atividade física ao ar livre. O que importa, neste contexto, é deixar o corpo em evidência e divulgar aos amigos e/ou seguidores das redes sociais que todo o esforço para a construção de uma imagem corporal desejada, vale a pena.

Por outro lado, tudo que não se remete ao belo, ao eficiente e ao que a sociedade coloca como padrão de referência, está cada vez mais longe dos holofotes e das mídias. Os corpos que estão na contramão dessa lógica de beleza, influenciados pela corpolatria, são representada pelos deficientes, obesos, magrelos, ou seja, pela alteridade.

O corpo na pós modernidade vem sendo ressignificado de acordo com a cultura e valores (pré) estabelecidos socialmente. Os padrões de beleza também vêm se transformando com o passar dos tempos, assim, amparados no que nos diz Freire (1979) 
"A cultura consiste em recriar e não em repetir". Cada cultura, neste contexto, pode evidenciar o que é belo ou o que é feio de acordo com suas características e seus valores sociais. Segundo Transferetti (2008), Antropólogos, sociólogos, filósofos, psicólogos e tantos outros profissionais têm se debruçado sobre a questão do corpo. Os filósofos, particularmente, têm procurado estudar o corpo mostrando a configuração de todo ser humano como um corpo que se comunica e se faz presente no mundo. O ser humano possui e ao mesmo tempo é um corpo. Um corpo que se comunica, que expressa, que ama, sendo através do corpo que, a princípio, caracteriza nossa identidade.

\section{Corpolatria: Panacéia da sociedade pós moderna}

O fenômeno da busca incessante pela melhor aparência estética ou pelo tipo físico idealizado, também denominado de corpolatria, prioritariamente associado aos praticantes de atividade física em academias, passou a ser um fenômeno sócio cultural muitas vezes mais significativo para quem pratica do que a própria satisfação econômica, afetiva ou profissional (NOVAES, 2001).

Entende-se por corpolatria uma espécie de "patologia da pós modernidade" caracterizada pela preocupação e pelos cuidados extremos com o próprio corpo (não no sentido da saúde), mas particularmente com no sentido narcisístico de sua aparência ou embelezamento físico (SENNE, 1995). A preocupação com a beleza, neste contexto, evidencia que é sempre um padrão externo ao desejo do indivíduo. O corpo parece emergir então como uma panacéia para todos os males, o caminho para a felicidade. Esse narcisismo atual em que as pessoas se preocupam em apresentarem-se esteticamente aceitas e dentro de alguns padrões, reforça a ideia da estetização, a partir da qual, buscase a "perfeição" a todo custo.

Para Baudrillard (1996), "A sedução narcísica vincula-se, a partir de então, ao corpo ou a partes do corpo objetivados por uma técnica, por objetos, por gestos, por um jogo de marcas e de signos". Podemos considerar que o corpo representa muitos valores e significados. Em outras palavras, o corpo ocupa um valor social importante na atualidade, em que esforços não são medidos para serem aceitos e valorizados.

Santos (1990), afirma que a corpolatria é uma expressão, a qual permite limitar o corpo numa condição de valor de uso e de valor de troca, em que "investir" no corpo é majorar o seu valor de troca, é colocá-lo em melhores condições para a aferição de lucros no mercado de bens simbólicos. Buscou-se a compreensão das questões da estética e da saúde nas 
http://dx.doi.org/10.5902/1984686X33142

academias a partir de um critério subjetivo de estética, ou melhor, de acordo com o velho adágio segundo o qual a beleza está nos olhos do observador (NOVAES, 2001). Segundo Fernandes (2005),

O corpo está em alta! Alta cotação, alta produção, alto investimento...alta frustração. Alvo do ideal de completude e perfeição, veiculado na pós modernidade, o corpo parece servir de forma privilegiada, por intermédio da valorização da magreza, da boa forma e da saúde perfeita, como estandarte de uma época marcada pela linearidade anestesiada dos ideais (FERNANDES, 2005, p.15).

Nesta linha de constatações, Novaes (2001), diz que "o senso de beleza é um traço universal da natureza humana. Ele é encontrado em todos os povos, todas as culturas, todas as épocas". Entretanto, Feijó (1992) esclarece que apesar deste conceito de beleza ser universal, o conteúdo daquilo considerado belo é relativo aos padrões de cada indivíduo, cada comunidade, cada época.

\section{A mídia e a espetacularização do corpo}

A mídia tem grande influência neste sentido, expondo em revistas, programas de tv e outros meios de comunicação, corpos cada vez mais magros e definidos, seduzindo e instigando as pessoas a entrarem nesta ditadura da beleza pós-moderna. Não podemos deixar de citar as redes sociais e mídias digitais, pois o "selfie" é um poderoso recurso de consolidação desses padrões no cotidiano. Deve-se levar em consideração também, os perfis das pessoas dedicadas às questões estéticas do corpo. Em relação à publicidade do corpo idealizado para Neto (2010), o processo é o mesmo.

O ser humano procura adquirir tudo o que as propagandas colocam como objetos de satisfação pessoal. Os corpos se transformam em busca de satisfação, o que na grande maioria das vezes, pode gerar angústia, pois as propagandas estão servindo aos interesses do sistema capitalista daquele momento.

\footnotetext{
Quanto mais a vida social se torna mediada pelo mercado global de estilos, lugares e imagens, pelas viagens internacionais, pelas imagens da mídia e pelos sistemas de comunicação globalmente interligados, mais as identidades se tornam desvinculadas - desalojadas - de tempos, lugares, historias e tradições específicos e parecem "flutuar livremente". Somos confrontados por uma gama de diferentes identidades (cada qual nos fazendo apelos, ou melhor, fazendo apelos a diferentes partes de nós) dentre as quais parece possível fazer uma melhor escolha (HALL, 2006, p.75).
}

A percepção do corpo passa a ser dominada pelas imagens reproduzidas pela mídia. Nas redes sociais surgem sujeitos comuns, reproduzindo ou contestando (com humor ou 
não) esses padrões estéticos. Através dessa idolatria corporal, as redes sociais "tiram de cena" as pessoas que não querem ou não alcançam esse "modelo" estético.

Para Campos (2010), no contexto atual, as pessoas estão sofrendo psiquicamente por não se encontrarem nos padrões de beleza que a mídia nos impõe, por falta de condições financeiras para as práticas corporais modificadoras, ou por não conseguirem atingir este padrão, sentem-se excluídas, marginalizadas, ridicularizadas. Fazendo uma análise neste contexto de ridicularização ao que se opõe ao modelo padrão estético, observamos como as pessoas obesas, idosas e deficientes muitas vezes são expostas nos programas de TV de forma pejorativa ou como um modelo a não ser seguido. Diante da forte influência midiática, especificamente, nas relações do corpo com a estética, as pessoas buscam a todo custo uma forma de corpo semelhante ao que a mídia coloca como referência, sendo uma busca incessante a este corpo padronizado.

\begin{abstract}
A percepção do corpo em geral e do próprio corpo em particular fica assim dominada pelas telas das imagens encenadas. Os videoclipes, as publicidades, as bancas de revistas destituem de sentindo não apenas todas as aparências que não se enquadram nos seus moldes, mas, mais do que isso, todos aqueles que ficam na sombra, às margens das luzes gloriosas do exibicionismo (SANTAELLA, 2004, p.131).
\end{abstract}

Sant'Anna (2001), coloca que na luta por alcançar pelo menos uma réstea de luz, a corrida rumo à juventude e à perfeição teleguiada "é hoje uma maratona que alcança jovens e idosos de diversas classes sociais, mas esses não conseguem ver o pódio, pois se trata de uma corrida infinita".É notório observar, principalmente em redes sociais, que este fenômeno da corpolatria faz com que as pessoas percam o bom-senso e o cuidado com a saúde para priorizar a estética e ser aceito socialmente por uma cultura que delimita/modela um corpo padrão. Mesmo que para isso, tenham que fazer uso exacerbado de medicamentos, cirurgias plásticas, dietas, dentre outros procedimentos estéticos que retardam o processo natural do ser humano, o envelhecimento. Esse "ritual" de penitência através de jejuns prolongados e o sacrifício nas academias, faz-se uma analogia do corpo com a religião, em que:

$\mathrm{Na}$ religião, milagre, exige sacrifício, e a corpolatria não pode deixar por menos; se quiser alcançar a graça pretendida, você terá que se submeter a PENITÊNCIAS: suar horas seguidas diante do espelho, estirar os músculos sem gemer de dor, emplastar os cabelos com vaselina colorida e continuar sorrindo, mastigar 100 vez (nunca 99 ou 101) um arroz duro e insosso, jejuar etc. Basta, pois nem os cristãos são de ferro (SENNE, 1995, p.12)

Neste contexto, foram criados "modelos" de referência quase inatingíveis, pois o corpo "vendido" passa distante da realidade da maioria. Esse novo discurso de corpo do sujeito 
http://dx.doi.org/10.5902/1984686X33142

pós-moderno revela também uma relação direta na perspectiva do poder, que a modernidade é ainda, segundo Foucault (1988), um tempo histórico no qual predomina o exercício de um biopoder articulado numa multiplicidade de práticas "positivas" de poder incidindo sobre a vida, tomando os corpos dos indivíduos como alvos e pontos de aplicação, investindo-os e produzindo-os conforme uma ordem moral, social, política, produtiva e normativa capitalista-burguesa. Notamos assim, que o sujeito da pós modernidade, assume, dentro da perspectiva do corpo historicamente construído, uma posição de "status", orgulho e emponderamento que o corpo belo e referencial lhe proporciona.

Deve-se levar em consideração também que o corpo tornou-se um produto capital e consumista, estabelecido pela sociedade como um produto. Na menção de Peres (2009) a imagem da corporeidade de nossa cultura racionalizada, cientifizada e industrializada, reduz o corpo a um objeto de uso em conformidade com os interesses econômicos, políticos e ideológicos de outros grupos ou classes sociais, fazendo com que o corpo se torne uma ferramenta de produção, que traria lucro e crescimento econômico ao meio no qual está inserido. Percebe-se assim que o corpo, ao longo dos anos, vem sendo vivido, percebido e interpretado pelas mais diversas técnicas e formas de controle, incorporando-se dentro dos mais variados meios de produção e consumo. São estas técnicas e formas de controle que Foucault (2001) chamou de tecnologias políticas do corpo.

Em consonância ao corpo como produto capitalista, nunca se investiu tanto em alimentação saudável, suplementação e uso indiscriminado de esteroides anabolizantes que são comuns no mundo fitness. Segundo Trasferretti (2008), a questão do corpo na sociedade capitalista está profundamente marcada pela cultura pós-moderna, que valoriza o corpo enquanto individualidade, capacidade de decisão, autonomia, liberdade, mas ao mesmo tempo produto cultural. Ou seja, essa cultura transitória pode ser derrubada ou modificada a qualquer momento. O que deve ser observado neste sentido seria como a idolatria exagerada ao corpo, principalmente das pessoas que ditam as regras dos padrões estéticos, fortemente marcado nas redes sociais e mídia, incentivam estratégias de emagrecimento e dietas milagrosas para todas as pessoas. Desconsideram a individualidade biológica, os limites e as particularidades acometidas a todos os indivíduos, ou seja, vai no caminho inverso da preocupação com a saúde.

Para ilustrar o quanto a indústria cultural brasileira tem se alinhado a esse modelo capitalista, poderíamos nos reportar ao tão difuso exemplo das revistas femininas, divulgadas amplamente e que atraem a atenção das mulheres de classe média alta e baixa, 
http://dx.doi.org/10.5902/1984686X33142

propondo indistintamente parâmetros de vida e beleza que são próprios das classes superiores. Devido a isso, os ideais que são propostos nessas revistas, se apresentam como modelos a serem seguidos (TRASFERETTI,2008). Esta lógica corporal estética provoca um paradoxo cultural acerca do deficiente físico que está fora dos referidos padrões impostos socialmente, excluindo-os deste contexto.

Ou seja, os deficientes físicos cadeirantes, amputados, ou com múltiplas deficiências, não atendem aos anseios desta sociedade marcada pela eficiência. O Homem possui um corpo com duas dimensões: uma orgânica e outra inorgânica. Sendo assim, acreditamos que o corpo orgânico é o meio direto de vida do ser humano, o objeto material e instrumento da sua atividade vital (MARX; ENGELS, 1971). Em outras palavras, considera-se que é através do corpo que manifestamos as marcas que nos posicionam socialmente: forte/fraco, branco/negro, eficiente/deficiente. É através do corpo também que criamos relações consigo mesmo, com o outro e com o mundo. Se tratando do corpo humano como meio de interação, Mendes (2004), afirma que:

\begin{abstract}
O corpo é sempre outra coisa que aquilo que ele é [...] enraizado na natureza no próprio momento em que se transforma pela cultura, nunca fechado em si mesmo e nunca ultrapassado. Quer se trate do corpo do outro ou de meu próprio corpo, não tenho outro meio de conhecer o corpo humano senão vivêlo, quer dizer, retomar por minha conta o drama que o transpassa e confundirme com ele. Portanto, sou meu corpo, exatamente na medida em que tenho um saber adquirido e, reciprocamente, meu corpo é como um sujeito natural, como um esboço provisório de meu ser total. Assim, a experiência do corpo próprio opõe-se ao movimento reflexivo que destaca o objeto do sujeito e o sujeito do objeto, e que nos dá apenas o pensamento do corpo ou o corpo em idéia, e não a experiência do corpo ou o corpo em realidade (MENDES, 2004, p.32).
\end{abstract}

Neste contexto, observamos que o corpo é parte determinante nas relações sociais e como ele se estabelece. Ao pensarmos sobre a lógica binária, em que classificamos as pessoas e através dessa classificação criamos uma imagem/conceito sobre tudo e todos, o eu eficiente está acima ou melhor classificado socialmente comparado a deficiente ao cadeirante, por exemplo.

\title{
O corpo deficiente e sua representação social
}

Desde a antiguidade o corpo já assumia um papel representativo nas sociedades. $\mathrm{Na}$ Idade média o corpo era atrelado a teia simbólica construída pela igreja católica sendo ao mesmo tempo divino, santo, quanto profano e pecaminoso. No período renascentista, a concepção de corpo se difere da anterior, apropriando-se do imaginário do homem, passando a significar algo belo e perfeito, especialmente no que diz respeito às artes. Aos poucos uma visão mais ampla do corpo vai se estabelecendo, abrindo caminho nos 
http://dx.doi.org/10.5902/1984686X33142

avanços dos estudos de anatomia e fisiologia. O corpo nas artes contemporâneas já não é mais visto como perfeito mas, um corpo vivido através de suas formas e desformas, assumindo assim a complexidade do homem (MAROUN; VIEIRA, 2008).

Sendo o deficiente físico considerado como minoria social comparado a um discurso que exalta um povo, uma raça e os valores que são repassados de geração em geração, tudo que não está presente nessa narrativa passa a ser desconstruído, repudiado e mal visto socialmente. Com isso, temos a criação de estereótipos que fixam uma ideia negativa e/ou pejorativa a respeito do outro, do que não está classificado e pautado dentro dos padrões sociais preestabelecidos. Bhabha (2005), discute essa questão através do estereótipo que é uma articulação social da diferença, da perspectiva da minoria, sendo uma negociação complexa em andamento, que procura conferir uma autoridade aos hibridismos culturais. Os embates de fronteira acerca da diferença cultural tem tanta possibilidade de serem consensuais quanto conflituosos, podem confundir nossas definições de tradição e modernidade, realinhar as fronteiras habituais entre o público e o privado, o alto e o baixo, assim como desafiar as expectativas normativas de desenvolvimento e progresso.

Assim, qual é o diferencial de um estereótipo? Estes se apossam das poucas características "simples, vívidas, memoráveis, facilmente compreendidas e amplamente reconhecidas sobre uma pessoa; tudo sobre ela é reduzido a esses traços, que são, depois, exagerados e simplificados. Então, o primeiro ponto é que a estereotipagem reduz, essencializa, naturaliza e fixa a "diferença" (HALL, 2016, p. 191)

Os estudos culturais apresentam uma gama de discussões acerca de alguns valores socialmente construídos, fortemente marcados pela discussão das minorias sociais, quebrando alguns paradigmas e regras sociais preestabelecidas. Essa desconstrução dos valores sociais permite que as ideias e concepções acerca destes assuntos sejam questionadas e repensadas, dando voz e espaço a essas minorias e reforçando o hibridismo cultural. No discurso do estereótipo e no campo das diferenças, vale ressaltar o distanciamento entre os corpos midiáticos, produtos do cinema, dos video-clips, dos quadrinhos e os monstros corporais reais, que, no contexto da corpolatria, não são outros senão os obesos e os deficientes.

A representação de um corpo multilado, deficiente ou um corpo fragmentado, sofreu grandes influências no processo histórico e cultural, em que sua espetacularização pela horror ou aberração foi evidenciada. Conforme Courtine (2008, p.226) os freaks shows no final do século XIX e início do século XX, na Europa e nos Estados Unidos, foram exemplos 
http://dx.doi.org/10.5902/1984686X33142

desta cultura voyerística, quando afirma que "a teratologia constituiu avanço crucial no conhecimento do ser vivo, pelo fato de ter mostrado pertencerem à espécie humana certas formas de vida que pareciam manifestar diante dela a mais irredutível alteridade". Portanto, os freaks-shows apresentavam corpos deformados como forma de divertimento, evidenciando, naquela época, como o corpo classifica e impõe o deficiente físico como minoria na sociedade. Andrade (2017) ressalta que o corpo freak trata-se de um corpo que irreconhecido, renegado e incompleto, que não cabe nos ideais da modernidade impostos por uma lógica de cultura capitalista ordenada por um padrão ainda vitruviano, por uma perfeição física. A história dessas aberrações, desses monstros, que foram denominadas como freaks, traz para ideia da alteridade no corpo.

Segundo Mendes (2012), o corpo considerado diferente em demasia era ridicularizado e utilizado como espaço preferencial de chacota e comédia sobre a vida pública e privada, funcionando como uma espécie de anestésico social. Neste contexto o corpo deficiente tinha sinônimo de monstruosidade, como pontua Foucault (2000), "o monstro humano combina o impossível e o interdito". Ou seja, os deficientes ou pessoas com alguma anomalia, na sua representação social, seriam e deveriam ser negados e excluídos. Segundo Fontes (2006), o corpo dissonante, exemplarmente ilustrado pelo corpo de pessoas deficientes físicas, só é atrativo e consumível (nos circos, por exemplo) na cultura de massa quando apresentado sob a configuração de espetáculo ou denúncia. Quando naturalizado e exibido sem artifícios, reduz-se a objeto causador de estranhamento e rejeição, por representar a negação ameaçadora do desejo de sedução e aceitação. Cohen, citado por Fontes (2006), discorre sobre a ideia da monstruosidade e relata:

Nós vemos o monstruoso espetáculo do filme de terror porque
sabemos que o cinema é um lugar temporário, que a vibrante
sensualidade das imagens de celulóide serão seguidas pela reentrada
no mundo do conforto e da luz. Da mesma forma, a história na página
à nossa frente pode aterrorizar (pouco importa se ela aparece na seção
de notícia do jornal ou no último livro de Stephen King), desde que
estejamos seguros por sabermos de seu fim próximo - o número de
páginas em nossa mão direita está diminuindo - e de que logo
estaremos livres dela (COHEN apud FONTES, 2006, p.130).

Já na pós modernidade esta analogia do corpo deficiente como forma espetacular ao horror foi questionada e repensada, mas ainda sim, vai à contramão dos adeptos a corpolatria, que em larga escala, constrói a nossa identidade exterior. De acordo com Fontes (2006), o corpo sem autonomia, limitado em sua capacidade de deslocamento e, por que não dizer, de encenação estética (vale ressaltar aqui que não nos referimos ao corpo doente, enfermo, mas apenas do ao corpo desprovido de uma função, um corpo 
limitado fisicamente), passa pelo mundo silenciosamente, praticamente invisível aos olhos sociais.

\section{Considerações Finais}

O culto exagerado ao corpo, como uma forma de representação social, faz com que os padrões de corpo preestabelecidos socialmente e culturalmente, fiquem cada vez mais em evidência. A mídia configura-se como uma das principais instituições que exerce forte influência nas construções identitárias, sendo responsável pela transmissão de grande parte de valores e padrões de conduta através dos mais diversos veículos de comunicação. Portanto, em uma sociedade que idealiza o corpo perfeito como referencial, faz com que o uso desta norma social como um ponto de ancoragem para a formação de autoconceitos, provavelmente este fator da valorização exagerada ao corpo belo tenha um impacto negativo nas pessoas com deficiência.

Enquanto estamos passando por um momento em que as pessoas não se permitem envelhecer, que a cobrança por um corpo magro, definido ou malhado produz pessoas com comportamentos obsessivos que movem um mercado milionário de cosméticos e produtos que retardam o processo de envelhecimento, os deficientes físicos e obesos estão na contramão desses valores. Neste contexto cultural do corpo soberano, o deficiente físico fica fora deste ambiente, pois seu corpo é silenciado pelos olhos sociais e midiáticos. Neste caso, fica claro que a mídia esconde a presença desse corpo "feio" ou "deformado" em nossa vida, sendo este "outro" escondido através dos processos cirúrgicos, dietas ou remédios. O deficiente, nesta situação, seria como símbolo vivo de fracasso, fragilidade e discriminação; um contraponto à normalidade; uma figura cuja própria humanidade questiona.

O corpo tem um papel fundamental na construção da identidade do sujeito, nele são impressos hábitos, valores, modelos e maneiras coletivas relacionadas a sua cultura. Sendo assim, principalmente para aqueles que apresentam algum tipo de deficiência física e que historicamente já carregam estereótipos que conotam uma imagem diferente por causa de suas deficiências, a construção de sua identidade social fica, na maioria das vezes, nas extremidades pejorativas.

Conclui-se, portanto, que há uma necessidade de repensarmos algumas questões sobre essa temática. Refletir sobre a representação do deficiente na sociedade e como ela se configura nos dias atuais. Alguns questionamentos devem ser levantados, como: Como 
http://dx.doi.org/10.5902/1984686X33142

pensarmos o corpo deficiente perante a lógica da eficiência imposta socialmente? Até quando o corpo deficiente ficará invisível aos olhos sociedade?

\section{Referências}

ANDRADE, Sueli. Chris Cunningham: Corpo e dejeto no vídeo contemporâneo. 2017. 120f. Tese (Doutorado em comunicação e semiótica). PUC, São Paulo, 2017.

BAUDRILLARD, Jean et al. A troca simbólica e a morte. São Paulo, Loyola, 1996.

BHABHA, Homi K. O local da cultura. Ed. UFMG: Belo Horizonte, 2005.

CAMPOS, Ivanir. A influência da mídia sobre o ser humano na relação com o corpo e a auto-imagem de adolescentes. Caderno de Educação Física Marechal Candido Rondon, v. 9, n. 17, p. 87-99, 2. sem., 2010.

COURTINE, J. J. "O Corpo Anormal - História e Antropologia culturais da deformidade". In: Corbin, Alain; Courtine, Jean-Jacques; Vigarello, Georges (org.) História do Corpo - As Mutações do Olhar: O Século XX - volume 3. Tradução e revisão: Alves, Ephraim Ferreira. Petrópolis: Editora Vozes, 2008.

FEIJÓ, O. G. - Corpo e Movimento. Rio de Janeiro: Shape, 1992.

FERNANDES, Maria H. Corpo. Clínica psicanalítica. São Paulo: Casa do Psicólogo, 2005.

FONTES, Malu. Uma leitura do culto contemporâneo ao corpo. Revista de Comunicação e Cultural. Vol.4 • n¹ p.117-136 Junho 2006.

FOUCAULT, Michel. A história da sexualidade, 1: A vontade de saber. 11. ed. Rio de Janeiro: Graal, 1988.

FOUCAULT, M. As palavras e as coisas. São Paulo: Martins Fontes, 2000.

FOUCAULT, M. Microfísica do poder. Organização e tradução de Roberto Machado. 16. ed. Rio de Janeiro: Graal, 2001.

FREIRE, Paulo. Educação e mudança. 24 ed, Rio de Janeiro: 1979.

HALL, Stuart. Da diáspora: identidades e mediações culturais. Editora UFMG, 2006.

HALL, Stuart. Cultura e representação/ Stuart Hall; Tradução: Daniel Miranda e Willian Oliveira. Rio de Janeiro: ed. Puc-Rio: Apicuri, 2016.

MAROUN, Kalyla; VIEIRA, Valdo. Corpo: uma mercadoria na pós-modernidade. Psicologia em Revista, v. 14, n. 2, p. 171-186, 2008.

MARX \& ENGELS; FRIEDRICH. A ideologia alemã e outros escritos: primeira parte. Rio de Janeiro: Ed. da UFRJ, 1971. 
http://dx.doi.org/10.5902/1984686X33142

MENDES, Maria Isabel. Corpo, natureza e cultura: contribuições para a educação. Revista Brasileira de Educação. Set /Out /Nov /Dez 2004.

MENDES, Enicéia Gonçalves; PICCOLO, Gustavo Martins. Nas pegadas da história: tracejando relações entre deficiência e sociedade. Revista Educação Especial. Vol 25, n 42 p. 32. Jan/Abr 2012.

NETO, INÁCIO. A influência da mídia sobre o ser humano na relação com o corpo e a auto-imagem de adolescentes. Caderno de Educação Física Marechal Cândido Rondon. v. 9, n. 17, p. 87-99, 2. sem., 2010.

NOVAES, Jefferson da Silva. Estética: O corpo na academia. Rio de Janeiro: Shape, 2001.

PERES, L. S. Corporeidade e sua relação com a Educação Física: um breve resgate histórico para entendimento. Caderno de Educação Física. Marechal Cândido Rondon, v. 8, n. 15, p. 53-61, 2009.

SANTAELLA, Lúcia. Corpo e comunicação: sintoma da cultura. São Paulo: Paulus, 2004.

SANT'ANNA, Denise Bernuzzi. Corpos de passagem. Ensaios sobre a subjetividade contemporânea, São Paulo, Estação Liberdade, 2001.

SANTOS, F.J. A. dos. Considerações sobre a corpolatria. Revista Motrivivência. p. 53-54, jan, 1990.

SENNE,W.A.O que é corpolatria. São Paulo: Brasiliense, 1995.

TRASFERETTI, José. O corpo e a cultura no contexto da sociedade brasileira. Comunicação e Informação. v.11,n.1,p. 126-137, jan-jun. 2008

\section{Correspondência}

Fabricio de Paula Santos - Universidade FUMEC. Rua: R. Cobre, 200 - Cruzeiro, Belo Horizonte. CEP: 30310-190. Belo Horizonte, Minas Gerais, Brasil.

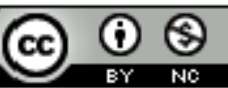

This work is licensed under a Creative Commons Attribution-NonCommercial 4.0 International (CC BY-NC 4.0) 